\title{
NEW FILLING MATERIAL FOR DIAMONDS FROM OVED DIAMOND COMPANY: A PRELIMINARY STUDY
}

By James E. Shigley, Shane F. McClure, John I. Koivula, and Thomas M. Moses

Diamonds filled with a new glass formulation (XL-21) are being marketed by the Oved Diamond Company. These diamonds are readily identifiable as treated by the intense flash-effect colors seen with magnification. Durability testing on a small number of these treated diamonds indicates that this filler material is more stable to conditions of normal jewelry repair, such as direct heating with a torch, than the filler material produced by the Goldman Oved Company a decade ago. Nevertheless, some damage to the filler was observed in half the new Oved diamonds that were subjected to a standard prong retipping.

\begin{abstract}
A number of comprehensive reports have been written on the characterization and identification of filled diamonds, most in the late 1980s and early to mid-1990s (see, e.g., Kammerling et al., 1994). Since then there have been few new developments in this area. Earlier this year, however, the Oved Diamond Company announced that they intended to market filled diamonds using a new glass formulation (referred to as "XL-21"; figure 1). Oved represented this material as being an improvement on past filler substances, with respect to having a
\end{abstract}

ABOUT THE AUTHORS

Dr. Shigley is director at GIA Research, Carlsbad. Mr. McClure is director of Identification Services, and Mr. Koivula is chief research gemologist, at the GIA Gem Trade Laboratory, Carlsbad. Mr. Moses is vice president of Research and Identification at the GIA Gem Trade Laboratory, New York.

Please see acknowledgments at the end of the article.

Gems \& Gemology, Vol. 36, No. 2, pp. 147-153.

(C) 2000 Gemological Institute of America greater resistance to heat damage during normal jewelry repair procedures; the company also stated that all of the new filled stones they sell will have an "Oved" logo inscribed on the bezel facet ("Oved announces . . . ", 2000; Weldon, 2000). This article will describe the visual characteristics of this new product, as well as report on the results of preliminary durability testing.

\section{BACKGROUND}

The clarity treatment of diamonds by filling surfacereaching cleavages or breaks with a high-refractive index glass began in the late 1980s (see, e.g., Everhart, 1987, 1989). Within a short time, this treatment became widespread. Concerns about the identification of these treated diamonds, and about their durability during jewelry manufacturing or repair situations, led to a series of articles that described this material (Koivula et al., 1989; Scarratt, 1992; Nelson, 1993, 1994; Kammerling et al., 1994; Nassau, 1994; McClure and Kammerling, 1995).

In recent years, however, both the greater availability of lower-clarity diamonds for treatment and 


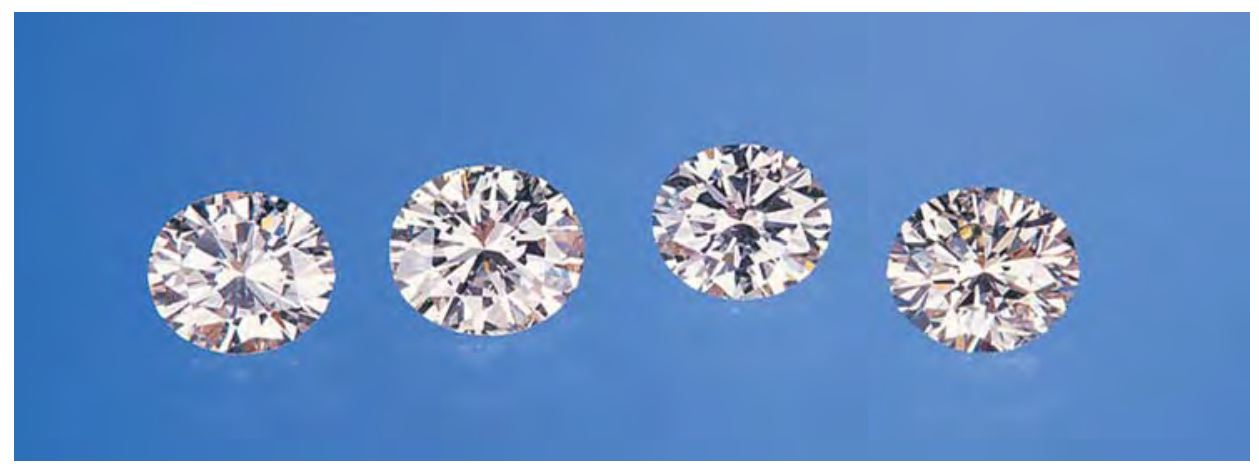

Figure 1. These four diamonds (0.35 to $0.44 \mathrm{ct}$ ) were all treated with a new filler formulation developed by the Oved Diamond Company. Photo by Maha Tannous.

the gradual acceptance of filled diamonds in the marketplace have contributed to ongoing efforts by manufacturers to develop more-durable filler substances. Several companies have been working to improve the physical properties of the glass filler used in this kind of diamond treatment. The Oved Diamond Company is the first of these to announce the commercial production of what they claim to be a significantly more heat-durable filler material. In their advertising (see, e.g., page 26 of the May 16, 2000, issue of National Jeweler), they state specifically that this new treatment "allows our clarity enhanced diamonds to withstand a jeweler's torch for all normal work-and come out unchanged. Which means that you can re-size and re-tip our diamonds without damaging the treatment."

\section{MATERIALS AND METHODS}

For this study, we examined 18 diamonds treated with the XL-21 filler substance. Fourteen of these were obtained directly from Oved, while the remainder were obtained from Oved through a third party. The diamonds, all round brilliants, ranged from 0.35 to 2.25 ct. For comparison purposes only, we also examined four diamonds $(0.49-0.61 \mathrm{ct})$, obtained from Jonathan Oved, that had been treated earlier by the Goldman Oved Company using an older filler substance of a different composition.

We examined all of these samples with a binocular microscope, and photographed the distinctive visual features with Nikon SMZ-10 and SMZ-U photomicroscopes. We also qualitatively analyzed the chemical composition of five samples (one with the older filler substance from Goldman Oved, and four-obtained directly from Oved-with the new XL-21 glass filler) using a Tracor Spectrace 5000 energy-dispersive X-ray fluorescence (EDXRF) system. The operating conditions selected were appropriate for detecting the heavy-atomic-weight elements anticipated to be present in the high-R.I. glass filler substance.

To get a preliminary idea of the durability of the new filler substance, we subjected some of the new Oved treated diamonds to a typical jewelry repair procedure - retipping of a prong — and direct thermal testing. The diamonds were examined with magnification after each test to check for possible damage to the filler substance. For each of these procedures, a Goldman Oved diamond containing the older filler compound was also tested at the same time and under the same conditions for comparison purposes.

For the retipping procedure, we had each of eight diamonds (five directly from Oved, and three from third parties) mounted in a $14 \mathrm{~K}$ yellow gold solitaire ring with a white gold four-prong head. For each ring, one prong was filed to form a flattened area to simulate wear, and this prong was retipped by a highly experienced bench jeweler. First, the diamond was given a firecoat of a saturated solution of denatured alcohol and boric acid powder. Next, a minute amount of fluxed solder was flowed onto the flattened area of the prong. A small amount of $14 \mathrm{~K}$ white gold was melted into a ball, flattened into a bead, and then fluxed and soldered into place on the flattened prong with a standard torch using natural gas and compressed oxygen. After this replacement prong was soldered, the ring was cooled in air to prevent thermal shock, and then placed for one minute in a hot pickling solution (temperature between $49^{\circ}$ and $60^{\circ} \mathrm{C}\left[120^{\circ}\right.$ and $\left.\left.140^{\circ} \mathrm{F}\right]\right)$ made of Sparex \#2. The ring was then placed in an acid-neutralizing bath and, last, rinsed with water. Although there are many procedural variables that are difficult to keep constant from one sample to the next (such as the length of time the torch is placed near the diamond, the exact temperature of the flame, and the extent and location of filled areas in the different diamonds), efforts were made to standardize these variables as much as possible in the experiments we conducted.

To determine the temperature at which visible damage to the filler material would occur, we placed three filled diamonds (two directly from Oved, and the other from a third party; each held in a refractory crucible) in the hot zone of a Blue M model M10A- 
1A Lab Heat muffle furnace. The temperature of the furnace was raised in $50^{\circ} \mathrm{C}$ increments, beginning at $100^{\circ} \mathrm{C}$ and extending up to about $750^{\circ} \mathrm{C}$; the samples were heated in air at each temperature for approximately 15 minutes, and then cooled and examined for damage. The accuracy of temperature measurements in this furnace was estimated to be within $\pm 20^{\circ} \mathrm{C}$ of the selected value.

\section{RESULTS AND DISCUSSION}

Visual Appearance and Magnification. Of the 18 samples treated with the XL-21 filler, 10 (eight from Oved, and two from third parties) did not exhibit the identifying "Oved" logo inscription on a bezel facet. According to Jonathan Oved (pers. comm., June 2000), the diamonds provided directly to GIA had not yet been sent for laser inscription. This also may have been the case with some of the earlier treated diamonds (these two third-party stones were obtained in April). On the eight diamonds that did have the inscription, it was seen easily with $10 \times$ magnification (figure 2).

As was reported for Yehuda filled diamonds as early as 1989, the most characteristic visual feature of diamonds filled with such a glass is the flash effect (see, e.g., Koivula et al., 1989; and the report on Yehuda, Koss, and Goldman Oved treated diamonds in Kammerling et al., 1994). This was also the case with the new Oved diamonds. Flash-effect colors are best seen with magnification (binocular microscope or loupe) and a focused beam of intense light. In our Oved samples, the flash effect was typically violetish blue to bluish green in brightfield and yellow to reddish orange in darkfield illumination (figure 3). These optical effects appeared brighter and more intense than we had observed in the Goldman Oved samples with the older filling material (see Kammerling et al., 1994).

In general, the breaks in the new samples were completely filled, except for small areas at the surface. When examined with magnification, these areas of incomplete filling resembled scratches (figure 4), as was reported for the older material (Kammerling et al., 1994, p. 158). Occasionally, the filled breaks had a slightly hazy or cloudy appearance, and some revealed a noticeable flow structure (figure 5). In several instances, the yellow to greenish yellow color of the filler was evident in large open cavities that were filled with the glass (figure 6). In one diamond, a filled laser drill hole was visible (figure 7).

We also noticed localized areas within several filled breaks where the glass was partially devitri-

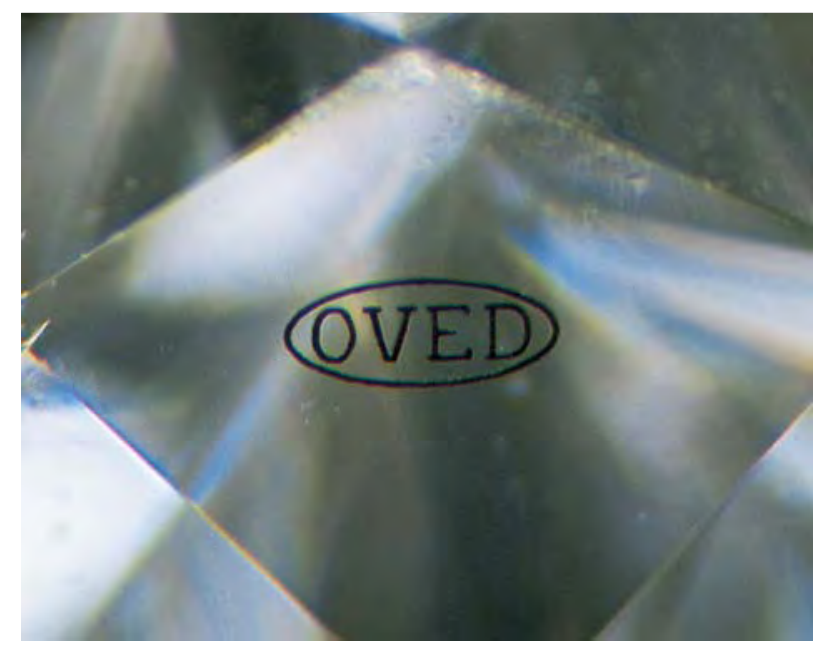

Figure 2. Oved announced that the "Oved" logo would be inscribed on a bezel facet of every diamond sold with the new filler. Photomicrograph by John I. Koivula; magnified 40x.

fied (i.e., it was beginning to crystallize, as evidenced by the presence of numerous tiny, elongate colorless crystals in intersecting arrangements; see figure 8). Trapped gas bubbles were present in many of the filled areas. While most were minute, a few in one diamond were almost eye visible. It is interesting to note that several of the diamonds showed a relatively even distribution of similar-size gas bubbles (figure 9). In contrast, the gas bubbles in the

Figure 3. This large filled break displays the various flash-effect colors that were typically seen in the new Oved glass-filled diamonds. Against a bright field, these colors are violetish blue; against a dark field, they are yellow or reddish orange. The colors are seen here against adjacent bright and dark backgrounds due to the orientation of the break relative to the facet arrangement. Photomicrograph by James E. Shigley; magnified 15x.

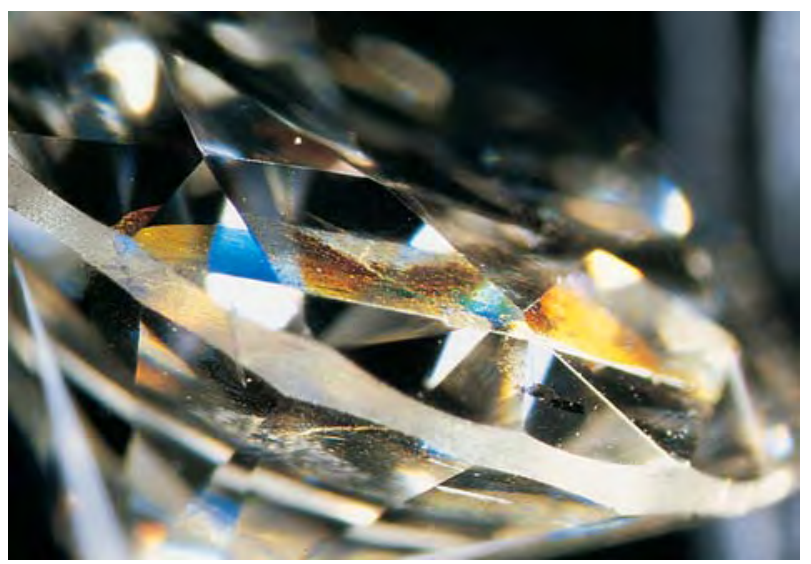




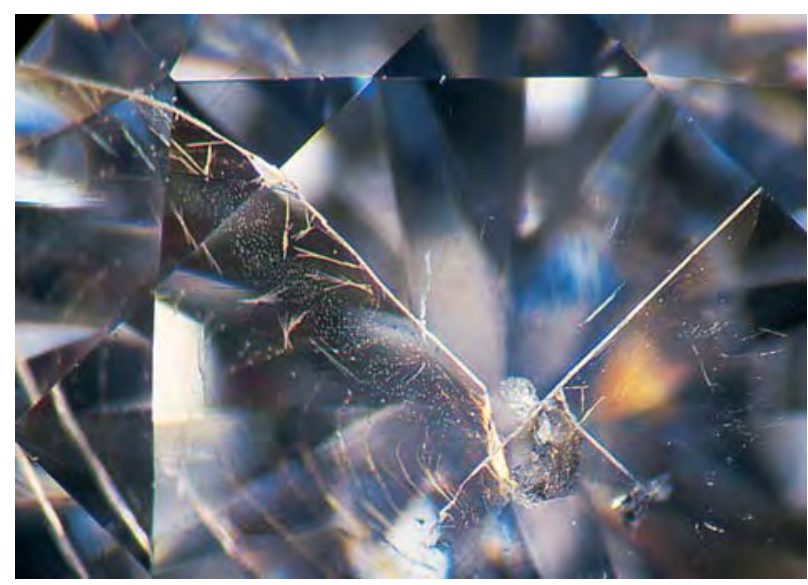

Figure 4. This break in a new Oved filled diamond displays small, unfilled areas at the surface of the stone that resembled scratches. Photomicrograph by Shane F. McClure, magnified 25×.

older Goldman Oved treated diamonds tended to form irregular, fingerprint-like patterns (Kammerling et al., 1994).

The filled areas were much more visible in the new Oved samples than in the old Goldman Oved treated diamonds. They were not difficult to locate, even without supplemental illumination. The easier visibility of the filled areas in the new material could be a result of the stronger flash effect, which makes these areas more apparent. It may also be that the refractive index of the new filler is not as close to that of diamond.

Figure 6. The greenish yellow color of the new filler is readily apparent in this filled cavity on the table facet of an Oved filled diamond. When present in a narrow cleavage, however, the glass appears colorless. Photomicrograph by John I. Koivula; magnified 15×.

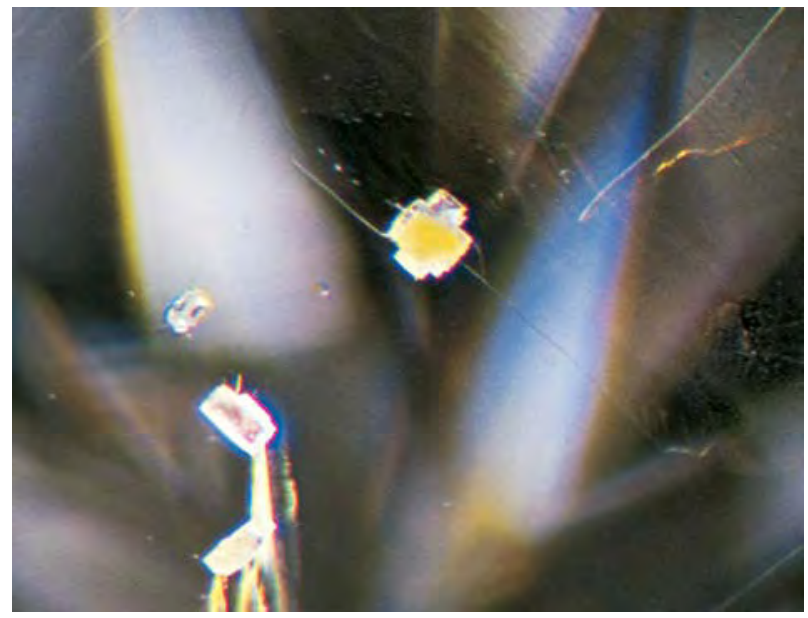

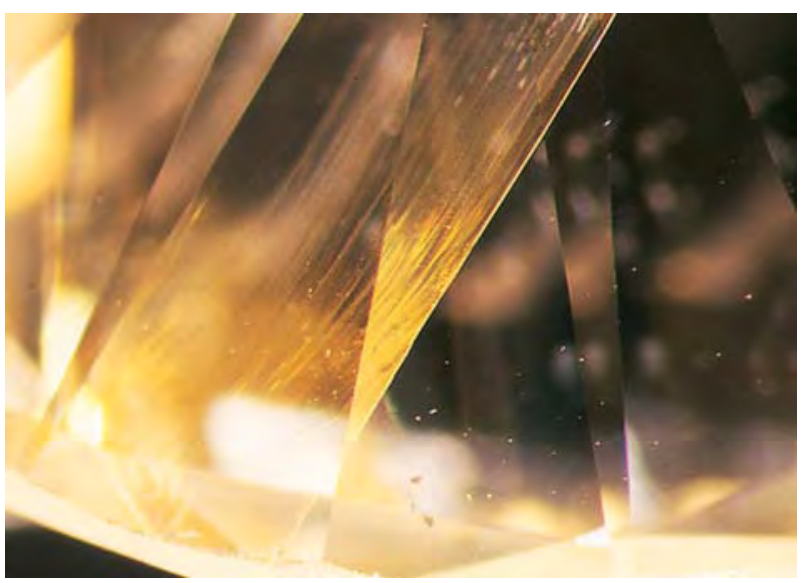

Figure 5. In some of the filled breaks, a distinct flow structure was seen. Photomicrograph by James E. Shigley; magnified 10x.

Chemical Composition. Using EDXRF analysis, we detected the presence of lead $(\mathrm{Pb})$ and bromine in a Goldman Oved diamond with the older glass filler (similar to the results in Kammerling et al., 1994, p. 161). In contrast, EDXRF analyses of four Oved diamonds filled with the new XL-21 glass formulation revealed both $\mathrm{Pb}$ and bismuth (Bi). (Typically, glasses also contain lighter atomic-weight elements, but such elements were not detected with the analytical conditions we used, or could not be detected at all by this technique.) $\mathrm{Pb}$ and $\mathrm{Bi}$ were the same two elements found in analyses of Yehuda filled diamonds (Koivula et al., 1989, p. 79; Kammerling et al., 1994, p. 161).

Durability Testing. Of the eight Oved filled diamonds that were subjected to the retipping procedure, four (two from Oved, and two from third parties) displayed minor damage in the form of lost filler material. This created unfilled areas within the fractures that appeared highly reflective (see, e.g., figure 10). The remaining four diamonds (three from Oved and one from a third party) exhibited no visible damage after the retipping procedure. Consistent with our experience in the early 1990s, the filler in the older Goldman Oved stone that was subjected to the same retipping procedure suffered major damage in the process. Consequently, the new Oved filler performed better in the retipping experiments than did the older Goldman Oved filling material.

Note that a number of variables may affect the retipping results. These include the size and width of the glass-filled breaks, their location relative to the area of the jewelry piece being repaired, the size of the diamond (our test samples ranged from 0.37 
to $1.34 \mathrm{ct}$ ), and the experience (skill) of the bench jeweler. This skill level is critical for the soldering technique used and controlling the torch in the soldering operation. In addition, the nature of the gold solder will have an impact. (We used 14K "easy" white gold solder in our study, with a flow temperature of $754^{\circ} \mathrm{C}\left[1390^{\circ} \mathrm{F}\right]$.) Platinum solders would always have a higher flow temperature. However, some $14 \mathrm{~K}$ solder as well as higher-karat golddepending on the manufacturer's formula (alloy)may have a higher or lower flow temperature (S. Kysilka, pers. comm., 2000).

Also, in recent communications with the authors, Jonathan Oved stated that the company uses approximately six glass formulations, each of which contains different mixtures of components, to enhance various kinds of clarity features. We speculate that this reported variation in glass chemistry could result in slight differences in the physical properties of the filler substance. Consequently, we believe that it is still advisable to remove any filled diamond from its setting prior to undertaking repair work that involves heating. Also, inasmuch as two of the third-party Oved diamonds did not have the "Oved" laser inscription, and other treaters do not offer such an inscription, all diamonds should be checked for the presence of a filler before they are subjected to any jewelry manufacturing or repair procedure.

Heating of a Goldman Oved diamond (i.e., with the older filler) in a muffle furnace resulted in significant damage to the glass filler at about $400^{\circ} \mathrm{C}$. Heating of the three new Oved diamonds also produced major damage, but at a much higher temper-

Figure 7. This laser drill hole was filled by glass during the Oved treatment process. Photomicrograph by Shane F. McClure; magnified 40×.

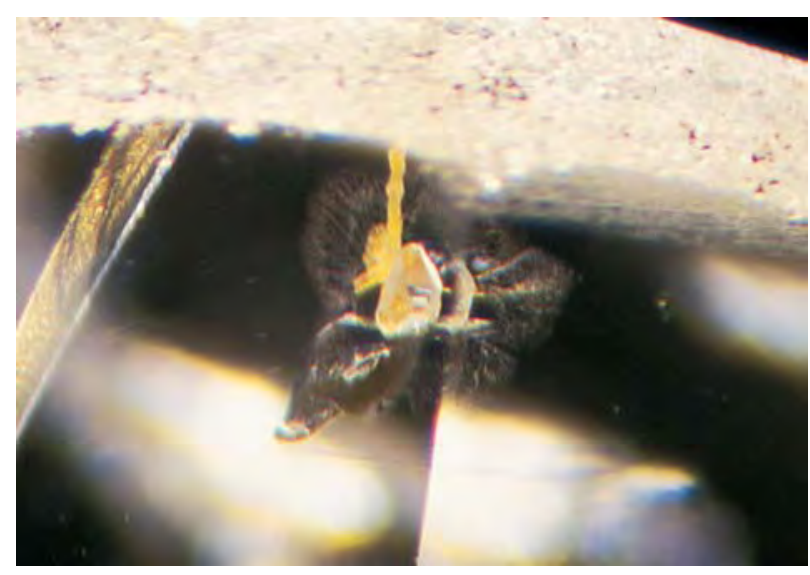

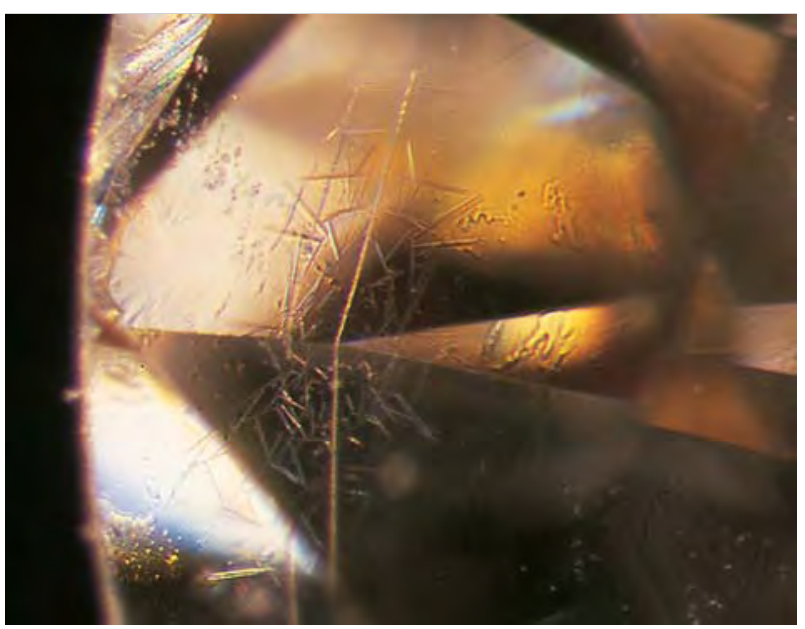

Figure 8. Arrangements of elongate, intersecting colorless crystals were seen in filled breaks in several of the diamonds where the glass was partially devitrified. Photomicrograph by James E. Shigley; magnified 15x.

ature, near $700^{\circ} \mathrm{C}$. A significant amount of filler material was lost, some of it depositing on the surface of the stone along the break (see figure 11). At this temperature, the diamonds themselves also showed signs of heat damage.

Yehuda Diamonds. As we were finishing this study, the Yehuda Diamond Company sent us five diamonds that they reportedly had filled with a temperature-resistant substance. Ron Yehuda stated that this formulation had been used on an experimental basis by their company in the mid-1980s,

Figure 9. In addition to a group of intersecting colorless crystals, this break in a new Oved filled diamond shows a pattern of gas bubbles that are relatively evenly dispersed. Photomicrograph by John I. Koivula; magnified 40x.

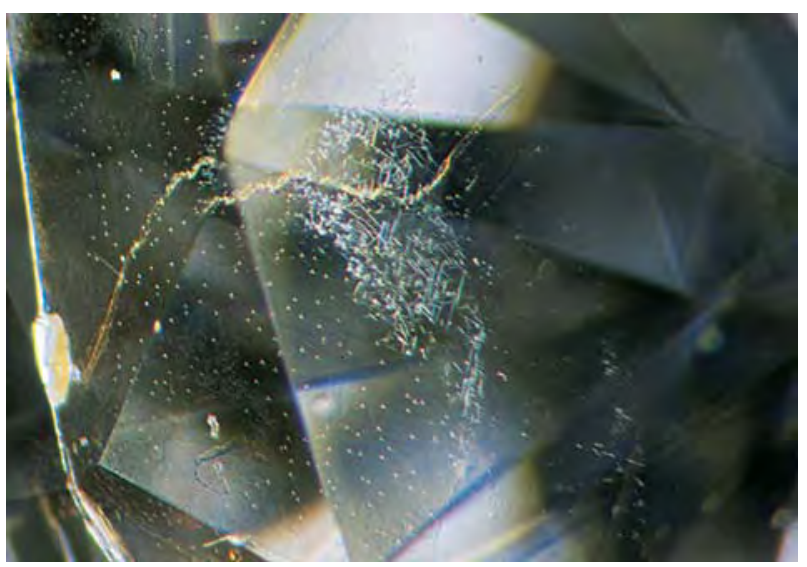



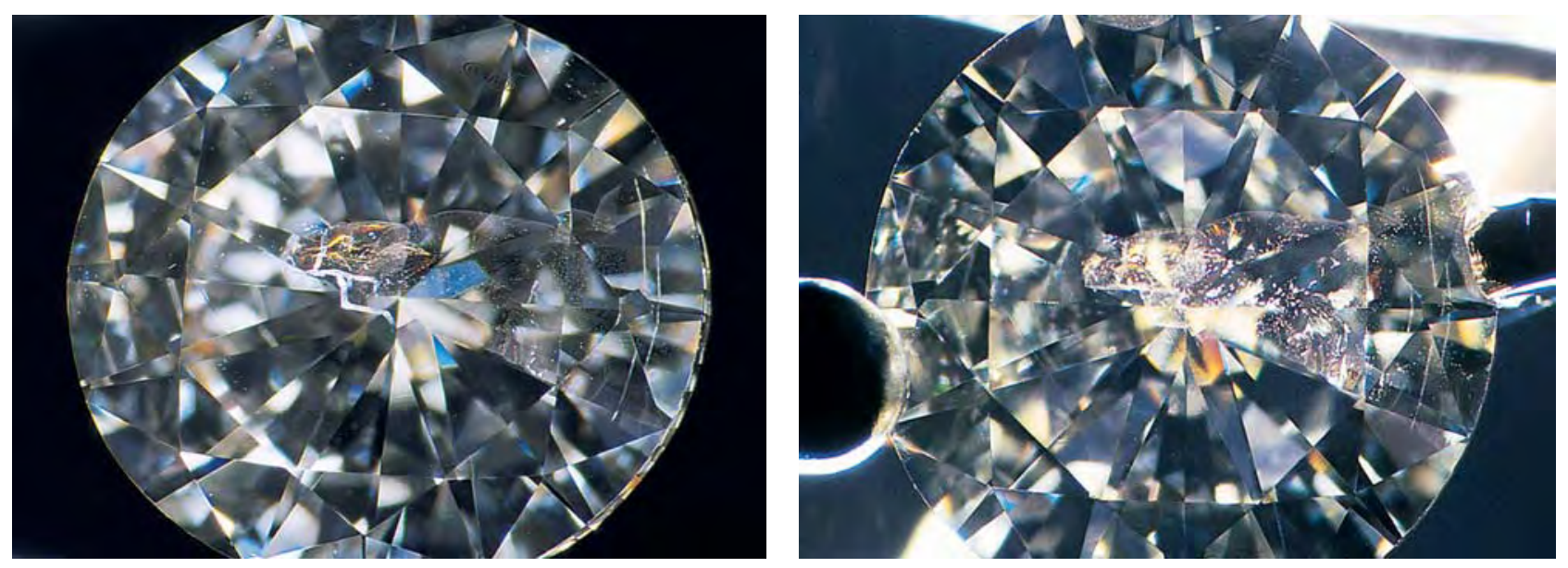

Figure 10. Four of the eight Oved diamonds tested showed minor damage after retipping. The photo on the left shows one of these diamonds (1.03 ct) before retipping. After the procedure (right), the glassfilled fractures showed a loss of filler that appears as reflective areas within the fractures. Photos by John I. Koivula (left) and Shane F. McClure (right).

but was not used commercially (pers. comm., 2000). Due to lack of time, we were not able to subject all of these stones to the durability tests that were performed on the Oved filled diamonds. However, we did test two of them by the retipping procedure, and a third by controlled heating in a muffle furnace, as described above. Of the two stones that were subjected to the retipping procedure, one showed no damage and the other had moderate damage. However, the stone that was subjected to controlled heating in the furnace showed damage at $400^{\circ} \mathrm{C}$.

Mr. Yehuda also supplied seven filled diamonds that he had obtained recently from the Oved Diamond Company through a third party (R. Yehuda, pers. comm., 2000). All seven stones were laser inscribed with the Oved logo. We subjected two of these samples to the retipping procedure: One showed major damage, and the other showed minor damage.

\section{CONCLUSION}

The new Oved glass-filled diamonds typically exhibit intense flash-effect colors, which make them readily identifiable by members of the jewelry trade. Oved states that they also will inscribe their logo on the bezel facets of all these new filled diamonds, although 10 of the 18 Oved diamonds in our test sample (including two obtained from Oved by a third party in the diamond trade), did not have this logo.

Figure 11. Note the filled break (with a yellow flash effect) along the right edge of this $0.35 \mathrm{ct}$ Oved filled diamond before it was subjected to durability testing (left). After the diamond was heated in a muffle furnace (in air) for 15 minutes at almost $700^{\circ} \mathrm{C}$, damage is evident in the filled area (right), as well as in the diamond itself (seen here as small whitish areas on the surface). Photomicrographs by John I. Koivula.
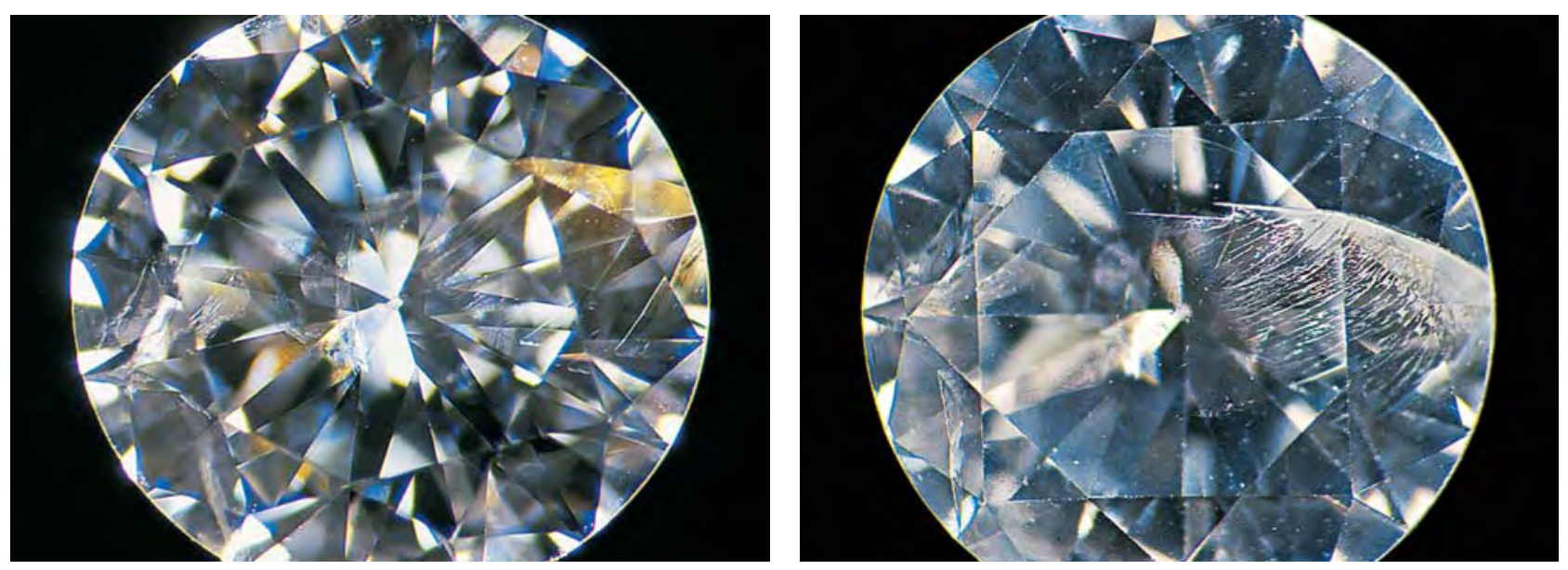
Durability testing of a few of the new Oved filled diamonds indicates that they are more stable to direct heat than the filled diamonds marketed earlier by Goldman Oved. Four of the eight new Oved diamonds were unaltered during the retipping procedure, and the other four sustained only minor damage. Nevertheless, we recommend that care be taken with all filled diamonds and, in particular, that all diamonds identified as containing a filler should be removed from the setting when a repair procedure requires heat.
Acknowledgments: The authors thank Jonathan Oved of Oved Diamond Company, New York, for providing study samples and information. Sherrie Kysilka and Larry Lavitt, of GIA Education's Jewelry

Manufacturing Arts Department, Carlsbad, performed the durability testing. Sam Muhlmeister, of the GIA Gem Trade Laboratory, Carlsbad, carried out the EDXRF chemical analyses.

GIA thanks De Beers and Argyle Diamond Mines Pty. Ltd. for their financial support of this research project.

\section{REFERENCES}

Everhart J. (1987) Diamond dealers balk at disclosure of new treatment. National Jeweler, October 1 Vol. 33 No. 2, pp. 1, 86.

Everhart J. (1989) Diamond treatment that removes flaws hits U.S. market. National Jeweler, January 16 Vol. 31 No. 17, pp. 1, 33.

Kammerling R.C., McClure S.F., Johnson M.L., Koivula J.I., Moses T.M., Fritsch E., Shigley J.E. (1994) An update on filled diamonds: Identification and durability. Gems «) Gemology, Vol. 30, No. 3, pp. $142-177$.

Koivula J.I., Kammerling R.C., Fritsch E., Fryer C.W., Hargett D., Kane R.E. (1989) The characteristics and identification of filled diamonds. Gems e) Gemology, Vol. 25, No. 2, pp. 68-83.

McClure S.F., Kammerling R.C. (1995) A visual guide to the identification of filled diamonds. Gems \&) Gemology, Vol. 31, No. 2 pp. 114-119.

Nassau K. (1994) On diamond-filling glasses and Nelson's speculations. Journal of Gemmology, Vol. 24, No. 3, pp. 183-184.

Nelson J.B. (1993) The glass filling of diamonds, part 1: An explanation of the colour flashes. Journal of Gemmology, Vol. 23, No. 8, pp. 461-472.

Nelson J.B. (1994) The glass filling of diamonds, part 2: A possible filling process. Journal of Gemmology, Vol. 24, No. 2, pp. 94-103.

Oved announces new clarity enhancement process (2000). Rapaport Diamond Report, Vol. 23 No. 16, May 5, p. 7.

Scarratt K. (1992) The clarity enhancement of diamonds. Diamond International, No. 19, pp. 45-58.

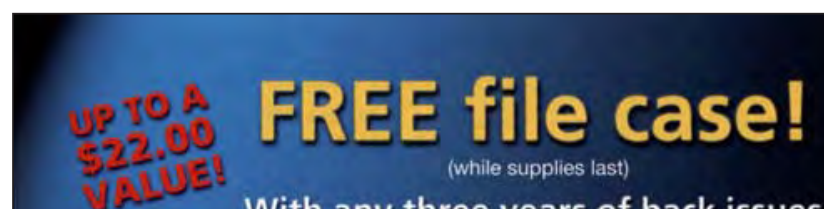

With any three years of back issues

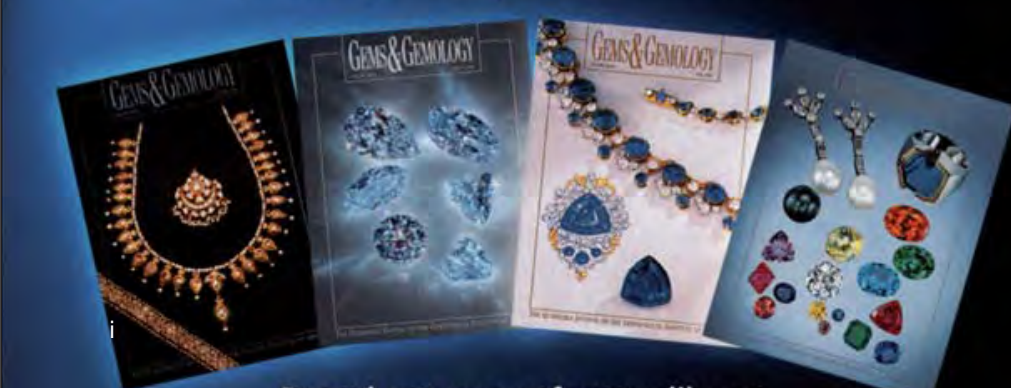

Round out your reference library with a leather-like file case embossed with the GEMS \& GEMOLOGY logo!

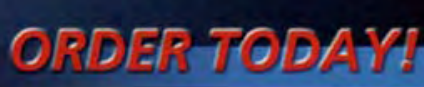

Call Toll Free $800-421-7250$ ext. 7142 or $760-603-4000$, ext. 7142

(Please see the ad on page 127 of this issue for a list of topics covered in specific back issues, and please mention this ad when ordering)
There's nothing like having what you need, when you need it. That's why no gemological reference library is complete without GeMs \& GEMOLOGY. In addition to in-depth research and gem locality articles, every beautifully illustrated issue features unique sections like Lab Notes and Gem News. Taken together, they provide a depth and breadth of gemological information you simply cannot find anywhere else. Take advantage of this special offer and complete your back issues today!

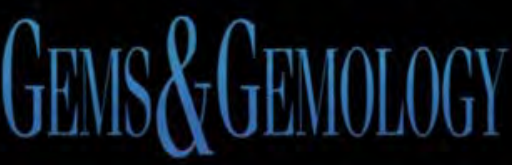

A wealth of information at your fingertips. 